\title{
O DISCURSO DE ÓDIO E A VIOLÊNCIA NELE CONTIDA
}

Giselle Morais Rocha*

\section{RESUMO}

O presente artigo tem por escopo relacionar o discurso de ódio com a violência nele contida, fazendo, inicialmente, uma breve análise da concepção filosófica de violência, com o intuito de conectá-la com o discurso de ódio na atualidade.

Passa-se pela ideia de que é difícil conceituar violência, pois esta depende da sociedade e da época em que vivenciada e analisa-se o conceito de discurso de ódio e a divergência que é traçada entre a visão mais liberal e a mais restritiva.

Ao fim, conclui-se que a democracia é a arma mais importante no discurso e contradiscurso.

PALAVRAS-ChAVES: Discurso de Ódio. Violência. Concepção Filosófica. Liberdade de Expressão. Democracia.

\section{HATE SPEECH AND THE VIOLENCE CONTAINED IN IT}

\begin{abstract}
The purpose of this article is to relate the hate speech with the violence, initially making a brief analysis of the philosophical conception of violence, in order to connect it with the hate speech today. The idea is that it is difficult to conceptualize violence, as it depends on society and the time in which it is experienced and the concept of hate speech and the divergence that exist between the liberal view and the restrictive. Finally, it is concluded that democracy is the most important achieved in discourse and counter-speech.
\end{abstract}

KEYWORDS: Hate Speech. Violence. Philosophical Conception. Freedom of expression. Democracy.

\section{INTRODUÇÃO}

A violência, por si só, não pode ser compreendida e estudada tendo como referência apenas os dias atuais. $\mathrm{Na}$ atualidade, ela está presente no corpo social, como esteve em tempo

\footnotetext{
* Graduada em Direito pela Universidade Mineira de Educação e Cultura. Mestranda em Instituições Sociais, Direito e Democracia no programa de Pós-Graduação Strito Sensu da Universidade FUMEC. Especialista em Direito Público pela ANAMAGES. É Analista Judiciário do Poder Judiciário Federal. Servidora do Gabinete da Diretoria-Geral do Tribunal Regional Eleitoral de Minas Gerais - TRE-MG, com experiência em assessoria jurídica de Juiz Membro da Corte do TRE/MG, em chefia de Foro Eleitoral e no Gabinete de Gestão da Informação e de Atos Partidários (SGI). Foi servidora pública do Ministério Público do Estado de Minas Gerais, com atuação jurídica na Promotoria de Justiça de Defesa da Saúde, área cível e criminal. Disponível em: http://lattes.cnpq.br/5146658346954929
} 
outrora. A violência pode se manifestar de diversas formas, na conduta, no discurso, no cinema, nas mídias sociais ou de qualquer outra maneira.

Embora a internet seja utilizada como veículo para manifestação de intolerância, discursos de ódio, preconceituosos e que desrespeitam a opinião alheia, não se pode olvidar que a história da humanidade se construiu baseada na dominação dos outros povos, na dominação da mulher, dos filhos, nas conquistas de territórios através da guerra, escravidão e morte.

O presente artigo tem como tema central o discurso de ódio e a violência na mensagem nele contida, tendo relevância devido à concepção, trazida pela autora, de que a violência sempre existiu nas sociedades, desde tempos antigos, e ainda existe em diversas formas, mormente se decorrente de insatisfações sociais.

Não se tem por escopo analisar a fundo a violência, mas sim relacionar o discurso de ódio com a violência nele contida, fazendo, inicialmente, uma breve análise da concepção filosófica de violência, para, após, tentar compreender se discursos com violência devem ser tolerados ou restringidos e as dificuldades que envolvem o tema.

A vertente metodológica deste artigo é jurídico-dogmática, com modelo de raciocínio dialético; o tipo de investigação é jurídico-compreensiva, levando-se em conta uma parte histórica apenas para contextualizar que a violência não é um fenômeno somente atual, e a breve concepção filosófica de violência para compreender que, para conceituá-la, parte-se da necessidade de um exame filosófico.

\section{POR UMA BREVE CONCEPÇÃO FILOSÓFICA DE VIOLÊNCIA}

Para compreender a violência, parte-se da necessidade do exame do homem no aspecto filosófico. Apenas a título de esclarecimento inicial, o objetivo deste artigo não é estudar e aprofundar acerca da violência. Contudo, a fim de melhor compreender o tema, é imprescindível uma breve análise na sua concepção filosófica.

Ao discorrer sobre a cultura e o valor da pessoa humana, Miguel Reale (2002, p. 206) discorre sobre a pessoa como valor fonte e tece que quando se estuda o problema do valor, 
devemos partir daquilo que significa o próprio homem, como único ser capaz de valores. $\mathrm{O}$ homem não seria apenas uma entidade psicofísica ou biológica, mas um ser com possibilidade de inovação e de superamento, que possui a faculdade de outorgar sentido aos atos e às coisas (o que chama de poder nomotético do espírito), faculdade de natureza simbolizante, a começar pela instauração da linguagem. Assim, há a consciência da dignidade e é a partir dessa autoconsciência que nasce a ideia de pessoa.

Discorre que basta confrontar o que nos cerca, para se impor a certeza de que a natureza é transformada pelo homem para satisfação de seus fins. Sobre a ordem das coisas naturalmente dadas, homem constitui um segundo mundo, que é o mundo da cultura. Chega à conclusão, portanto, de que o problema do valor se reduz à própria espiritualidade humana. Há possibilidade de valores porque quem diz homem diz liberdade espiritual, possibilidade de escolha constitutiva de bens.

Assim, somente haveria violência para o homem, como ser capaz de dar sentido e significado às coisas, diferentemente dos animais.

$\mathrm{O}$ autor tece que, ao examinarmos os acontecimentos históricos, há experiências felizes ou não no tempo, mas sempre no propósito de dominar a natureza e de estabelecer formas de convivência. Citando Spranger (1948, apud REALE, 2002, p. 229) ${ }^{1}$, o autor faz a correlação entre atos espirituais e valores dominantes, implicando estruturas típicas ou "formas de vida",2.

Através da História encontram-se fases ou épocas que se distinguem por certa ordenação da vida social, estando os valores suscetíveis de uma ordenação gradual, pois há épocas em que a sociedade parece dominada pelo valor do religioso, como por exemplo na Idade Média, de maneira que em torno desse valor se ordenam todos os demais. ${ }^{3}$

Dessa forma, é difícil conceituar violência, pois se deve levar em consideração que ela depende das relações pessoais, política e cultural de uma determinada sociedade, e da época em que vivenciada. Jayme Paviani, ao tratar da origem do termo violência, do latim violentia,

\footnotetext{
${ }^{1}$ SPRANGER, Eduardo. Formas de Vida, Rev. Do Occidente, Buenos Aires, 1948.

2 Segundo Spranger, é possível distinguir entre seis tipos ideais de homem, segundo os quais se pode compreender os tipos mistos da experiência histórica: o homem teor ético, dominado pelo valor da verdade; o homem econômico, absorvido pela estimativa do útil; o homem estético atraído pelo valor do belo; o homem social, conduzido pelo valor do amor; o homem político, determinado pelo valor do poder e; por fim, o homem religioso, embebido do valor do santo (1948, apud REALE, 2002, p. 229).

${ }^{3}$ São as épocas chamadas "teocêntricas", que põem o problema religioso no centro da existência total. Outras épocas, ao contrário, são dominadas pela estimativa do econômico, imediatista e pragmática.
} 
denomina -a como o ato de violar outrem ou de se violar. Além disso, o termo parece indicar algo fora do estado natural, algo ligado à força, ao ímpeto, ao comportamento deliberado que produz danos físicos tais como: ferimentos, tortura, morte ou danos psíquicos, que produz humilhações, ameaças, ofensas. Dito de modo mais filosófico, a prática da violência expressa atos contrários à liberdade e à vontade de alguém e reside nisso sua dimensão moral e ética (MODENA, 2016, p. 8). ${ }^{4}$

Segundo ele, as teorias da violência são necessárias para descrever, analisar e interpretar tal fenômeno. Elas podem ser científicas, filosóficas ou mistas. São mencionadas, entre outras, as teorias sociológicas, psicológicas, psicanalíticas, biológicas, jurídicas e feministas. ${ }^{5}$

Numa teoria biológica, a violência teria como âmbito o instinto de superação dos conflitos na luta pela sobrevivência. Nesse ponto, pode-se estender a reflexão a Cesare Lombroso, para o qual a herança biológica explicaria o comportamento agressivo. ${ }^{6}$

Para Arendt (1985, p. 34 apud MODENA, 2016, p. 12), dizer que violência se origina do ódio é um lugar comum. O ódio não é uma reação automática à miséria e ao sofrimento, pois ninguém reage com ódio a uma doença incurável ou a condições imutáveis. O ódio só surgiria onde há razões para suspeitar que as condições podem ser mudadas, quando o senso de justiça for ofendido. Por tal motivo, considera que na vida pública ou privada, há situações em que uma ação violenta é o único remédio adequado (ARENDT, 1985, p. 34).

Citando Sorel (ARENDT, 1985, p. 37), em seu livro Reflexions sur la violence, é pouco provável que possa haver uma moral ou uma doutrina política ou social que sustente que a violência é justificável por si mesma, mas pode ser considerada justificável como condição para manutenção da ordem considerada legítima. Portanto, ela seria meio e não fim. ${ }^{7}$

\footnotetext{
4 O autor sustenta que o conceito de violência é tão amplo que dificilmente as classificações abrangem todas suas formas.

${ }^{5} \mathrm{O}$ autor se refere a teorias psicofísicas quando há influência de substâncias químicas ou elementos psicológicos drogas, punições, ódio e stress.

6 Teoria do delinquente nato, o homem delinquente possuiria uma série de características e estigmas degenerativos comportamentais, psicológicos e sociais que reportavam ao comportamento de certos animais e tribos primitivas selvagens (LOMBROSO, 2010, p. 43-44).

${ }^{7}$ Georges Eugene Sorel, 1847-1922.
} 
Para Weil, o ser humano é o único a revelar a violência. Os animais podem ser violentos, mas só na visão dos homens, pois só o homem conhece e designa a violência, o absurdo, o sem sentido (WEIL, 1990, p.77-87).

Para Kar R. Popper, em “A Sociedade Aberta e seus Inimigos”, a civilização ainda não se recuperou de todo do choque inicial de seu nascimento - da transição da sociedade tribal, com sua submissão às forças mágicas, a que ele chama de sociedade fechada, para a sociedade aberta, que põe em liberdade as faculdades críticas do homem. O choque dessa transição seria um dos fatores que possibilitaram o surgimento dos movimentos reacionários que tentaram e ainda tentam derrubar a civilização e retornar ao tribalismo (POPPER, 1974).

Slavoj Žižek, filósofo psicanalista, ao abordar os conceitos de violência, tece sobre a subjetiva (visível, exercida por um sujeito claramente identificável e que é percebida como uma perturbação do estado "normal” das coisas), a simbólica (contida na linguagem e suas formas), e parte para seis visões marginais sobre a violência na pós-modernidade, fazendo uma crítica da constelação global, frente à qual não se oferece solução clara e nem se explica o que gera a violência.

Em seu livro "Violência: seis reflexões laterais" critica a direita, a esquerda, o capitalismo e mistura, de forma muitas vezes confusa, vários filósofos em poucos parágrafos e traz a concepção de que na violência pode estar incluída uma mudança institucional. Na sua visão crítica, chama de comunistas liberais alguns atores e enumera até dez mandamentos destes. $^{8}$ Defende que o capitalismo atual precisa de caridade extraeconômica para a manutenção de seu ciclo de reprodução social. Dessa forma, a situação é agravada pela póspolítica, que deixa para trás os velhos embates ideológicos para se centrar na gestão da administração despolitizada.

Referindo-se à história do trabalhador que é inspecionado todos os dias ao sair da fábrica com um carrinho de mão, e nada se achava contra ele, até que "cai a ficha" de que ele furtava os carrinhos de mão, o autor relata que há um paradoxo semelhante na violência, no

\footnotetext{
${ }^{8}$ Traz a ideia de que comunistas liberais são grandes executivos que trazem como dogmas uma versão nova e pós moderna de mercado: o mercado e a responsabilidade social não se opõem. São pragmáticos e odeiam abordagens doutrinárias. São dez os seus mandamentos: 1. forneça tudo de graça, cobrando apenas pelos serviços adicionais; 2. transforme o mundo; 3. consciência das responsabilidades sociais; 4. seja criativo, concentre-se nas novas tecnologias; 5. diga tudo: não deve existir segredos; 6. não trabalhe com horário fixo das 09 às 17 hs; 7. volte aos estudos; 8. não trabalhar só para o mercado, mas para promover novas formas de colaboração social; 9. morra pobre; 10. defenda o Estado: praticar parcerias entre empresas e o Estado (ŽIŽEK, 2014).
} 
sentido de que a alta potência do horror de atos violentos e a empatia com as vítimas funciona como um engodo que nos impede de pensar, pois os sinais mais evidentes são de crime e terror, mas que devemos dar um passo atrás para desembaraçar-nos do engodo desta violência subjetiva diretamente visível. Isso porque na sociedade contemporânea é comum a violência objetiva, aquela inerente ao estado "normal" das coisas, por causa da ideologia subjacente ao discurso liberal do sistema capitalista, que arruína milhares de vidas, e qual tal violência é vista como um "mal necessário" no mercado global. ${ }^{9}$

Outrossim, discorre sobre a distinção entre dois modos opostos, mas complementares, de violência: a violência sistêmica ou "ultraobjetiva", própria às condições sociais do capitalismo global (que implica a criação de indivíduos excluídos, como desempregados e sem-teto), e a violência dos novos "fundamentalismos" emergentes, de caráter étnico ou religioso.

Quanto à pós-política, é essa a que deixa para trás os velhos combates ideológicos para se centrar na gestão especializada, enquanto a biopolítica designa como seu objetivo principal a regulação da segurança e do bem estar das vidas humanas. Com a administração especializada, despolitizada e socialmente objetiva, uma pós política dessa natureza assenta-se na manipulação de uma multidão paranóica. A única maneira de introduzir paixão nesse campo é através do medo: medo de imigrantes, medo da criminalidade, da depravação sexual, etc. Essa concepção da violência como medo do outro seria "uma reação à desintegração das barreiras protetoras que mantinham os outros a uma distância adequada. O outro seria um "intruso traumático", alguém cujo modo de vida é diferente e nos perturba, causada pela ruptura do mundo ocidental com a religião, pois a ciência hoje, que nos forneceria certeza e segurança, compete com a religião, que outrora as garantia. Numa curiosa inversão, a religião é hoje um dos lugares a partir dos quais formulamos dúvidas, críticas sobre a sociedade e transformou-se em um dos "locais de resistência".

Assim, o caráter destituído de mundo do capitalismo está ligado a esse papel hegemônico do discurso científico na modernidade: para nós modernos, a arte e religião já

\footnotetext{
${ }^{9}$ Para o autor, opor-se a todas as formas de violência - da violência física e ideológica, parecer ser a maior preocupação da atitude liberal tolerante que predomina atualmente; contudo, entende que este discurso abafa todas as outras abordagens possíveis: todo o resto pode e deve esperar.
} 
não impõem um respeito absoluto como a ciência, e que há um impacto desagregador da modernidade sobre o modo de vida, conduzindo a uma "crise de sentido". Defende que na Europa houve tempo para trabalhar a adaptação dessa ruptura (cultura), mas em algumas sociedades, como a muçulmana, não. Estas foram expostas a esse impacto sem barreira de proteção, ou seja, perderam seu fundamento sem tempo suficiente para um equilíbrio.

Indaga: por que motivo temos hoje tantos problemas percebidos como questões de tolerância, mais do que de desigualdade, exploração ou injustiça? A resposta imediata residiria no que chama de "culturização da política", ou seja, as diferenças políticas condicionadas pela desigualdade política ou pela exploração econômica - são naturalizadas e neutralizadas em diferenças "culturais", em diferentes modos de vida. A causa dessa culturização é o fracasso das soluções políticas diretas, como o Estado de bem-estar social. A tolerância seria seu substituto pós-político. ${ }^{10}$

Assim, numa interessante percepção, o autor foge da visão mais visível da violência, pois aborda não somente a dimensão da violência subjetiva, mas também da violência objetiva e simbólica.

Žižek defende ainda que o ódio é um dos elementos de luta do homem, partindo da rejeição de uma falsa antiviolência, chegando-se à aceitação da violência emancipatória. Para ele, estigmatizar a violência é uma operação ideológica, uma mistificação que colabora no processo de tornar invisíveis as formas de violência social.

Por fim, discorre sobre a violência divina, afirmando que não existem critérios objetivos que nos permite identificar um ato de violência como divino. O mesmo ato, que para um observador de fora não passa de uma explosão de violência, pode ser divino para os que nele participam.

Lado outro, pode-se fazer a conexão dessa visão visível da violência no âmbito da Criminologia. O marco científico nesse campo se inicia com a criminologia europeia, baseada no estudo no positivismo criminológico, através do método de observação dedutivo para

\footnotetext{
${ }^{10}$ Ainda com relação à noção liberal de tolerância, mas sem aprofundar sobre o seu conceito (tolerância), o filósofo descreve que só na moderna cultura ocidental que a autonomia e liberdade individual são postas acima da solidariedade coletiva, da responsabilidade pelos outros e da obrigação de respeitar os usos da comunidade a que cada um pertence (ŽIŽEK, 2014).
} 
explicar as causas do delito e o comportamento do criminoso a partir de anomalias biológicas, que trouxe a criminalidade como sinônimo de doença. ${ }^{11}$

Remetendo à violência sistêmica, Douglas Fisher, em seu artigo denominado "O Custo Social da Criminalidade Econômica", cita que José Ricardo Sanchis Mir e Vicente Garrido Genovês, na conhecida obra intitulada "Delincuencia de Cuello Blanco" (1987, p. $91)^{12}$, suscitam que a falta de violência direta de enfrentamento com a vítima e a não intencionalidade de dano físico são dados a serem considerados na explicação dos motivos de as pessoas reagirem, diante dos delitos de colarinho-branco, com certa neutralidade moral. $\mathrm{Ou}$ seja, não há sangue visível e, por isso, há defensores de penas mais brandas (SOUZA, 2011, p. 29).

Diante do quadro de criminalidade aparente e de criminalidade oculta, Sutherland estudou o tratamento dado a criminosos de classes altas e de classes baixas, desenvolvendo a teoria da associação diferencial, que se assenta na ideia de que o comportamento criminoso é consequência de um processo de aprendizagem que se desenvolve no meio em que o crime é cometido (SUTHERLAND, 1999). Todavia, os delitos de colarinho-branco possuem efeitos muito mais devastadores sobre a sociedade que os delitos comuns, os quais têm relativamente pouco efeito sobre as instituições e a organização social. Os delitos de colarinho-branco podem incidir de um modo mais direto na delinquência comum, pois criam mais pobreza, mais miséria e desesperança. Geram, portanto, mais violência sistêmica e, consequentemente, a subjetiva.

Mas voltando a Žižek, o que seria a liberdade individual exposta pelo autor, aquela que, na sociedade ocidental, está acima da solidariedade coletiva? O autor não aprofunda nesse assunto. Todavia, podemos relacioná-la em suas bases.

Alysson Leandro (2018, p. 148) faz uma digressão acerca do individualismo. Para o pensamento clássico grego, o homem é pleno quando é cidadão. O paradigma está nas

\footnotetext{
${ }^{11}$ Contudo, essa visão originária não se ajustava à realidade social dos séculos XVIII e XIX, nos quais emergiam grandes revoluções devido às condições econômico-sociais e, nos Estados Unidos da América, outras foram as explicações para o crime, devido à necessidade de controle da criminalidade ligada ao crescimento do desenvolvimento norte-americano.

${ }^{12}$ Sanchis Mir e Garrido Genovês, em sua obra original, fazem referência aos seguintes autores: Ross, 1907; Sutherland, 1940; Clinard; Quinney, 1973; Fattah, 1976; WalSh; Schram, 1980; Shranger; Short, 1980; Vaughan, 1980; Tomlin, 1980; Stotland.
} 
virtudes políticas, e a virtude da justiça, segundo Aristóteles, é bem para o outro, exercendose na sociedade.

Já para a filosofia medieval cristã, dá-se ênfase na virtude individual, da criatura ligada ao criador, com sua fé, sendo o fenômeno da salvação tido por individual. Não importa, aos medievais, salvar o mundo, que é corrompido, e sim a conquista individual do mundo eterno.

Os modernos, por sua vez, rompem com essa tradição, pois buscam compreender o mundo não pela fé, mas racionalmente, não havendo, conforme os medievais, a ideia de que o soberano possua poderes divinos (MASCARO, 2018, p. 149).

Assim, o individualismo remonta ao contrato social e às origens do pensamento democrático, com Hobbes, Locke e Rousseau, e à rejeição do poder absoluto. O indivíduo é um ser uno, livre e responsável por seus próprios atos.

As teorias contratualistas, desenvolvidas na modernidade, postularam a ideia de que há no início da vida social apenas homens, e esses homens são iguais em natureza. Para os modernos iluministas, há um novo paradigma filosófico: é em função do indivíduo e de seus interesses e direitos fundamentais que deve ser posto o Estado, e as leis morais e jurídicas pensadas racionalmente pelo homem devem atender a esse individualismo originário, de igualdade formal entre todos e em atenção à liberdade individual.

A ideia dos direitos subjetivos e de liberdade individual está ligada à consolidação das bases do sistema capitalista, que requer indivíduos juridicamente livres e iguais.

Para os modernos, o estado de natureza é a condição primeira dos indivíduos na história, antes da vida social, na qual os homens são livres. Os homens deixam de viver nesse estado natural e passam a viver em sociedade, por variadas razões.

Para Thomas Hobbes (1588-1679), teórico do absolutismo que inova ao extraí-lo de um contrato social, a vida em natureza não possibilita ao homem a convivência pacífica. Há a guerra de todos contra todos. A sociedade civil, e o Estado que lhe advém, garantem a ordem não havida no estado de natureza. Para John Locke (1632-1704), filósofo que articula uma teoria do contrato social contra o absolutismo, a sociedade permite uma ordem racional de convívio, e o objetivo desta é a liberdade e a garantia da propriedade privada. Nesse sentido, dá um passo decisivo em direção ao liberalismo, pois a propriedade está entranhada como direito natural do indivíduo, não podendo o Estado desrespeitá-la. Segundo Jean-Jacques Rousseau (1712-1778), o homem, em estado de natureza, é bom. Passa a viver em sociedade e 
esta surge com a propriedade. A propriedade, por sua vez, engendra a corrupção dos homens, a violência. Somente um contrato social, baseado na razão, pode num momento posterior estabelecer um homem diferente, com valores transformados e racionais (MASCARO, 2018, p. 176-192).

Destarte, o paradigma individualista foi extremamente importante para o rompimento com a ideologia absolutista e não implica apenas uma postulação filosófica quanto à explicação das origens da sociedade. O individualismo surge como um programa político da burguesia para a atuação na sociedade do seu tempo.

Contudo, na concepção contemporânea, há a defesa de que o problema ético vem do fato de que, na civilização ocidental, tende-se a favorecer o programa egocêntrico, baseado numa sociedade marcada pela cultura da imagem, pelo prazer instantâneo e pela busca de satisfação pessoal como valores predominantes. Tais características, infere-se, pode estar relacionada ao aumento da violência no mundo contemporâneo.

\section{O DISCURSO DE ÓDIO E A VIOLÊNCIA CONTIDA NELE}

Após essa breve concepção filosófica da violência, decerto que não se pode falar de discurso de ódio sem se referir à violência contida nele em sua contemporaneidade. No artigo “A Desconstrução da Imagem e a Propaganda Eleitoral no Rádio e Televisão" ((ROCHA, 2020, p. 103 $)^{13}$, discorre-se sobre o conceito trazido por Maxime Lepoutre, em Hate Speech in Public Discourse: A Pessimistic Defense of Counterspeech, no qual se define discurso de ódio, a grosso modo, como comunicações que enfaticamente negam o status básico de outros membros da sociedade como cidadãos livres e iguais. Seria negar a posição básica dos indivíduos pertencentes a grupos sociais vulneráveis, em virtude de pertencerem a um determinado grupo. Para alguns estudiosos, o dano envolvido no discurso de ódio justifica

\footnotetext{
${ }^{13} \mathrm{O}$ artigo teve o escopo de analisar a restriçãa à propaganda eleitoral no rádio e televisão em contraponto à garantia constitucional à liberdade de expressão e os possíveis efeitos da propagação da mensagem, relacionada à desconstrução da imagem e da personalidade dos candidatos. Para tanto, foram analisadas decisões judiciais proferidas pelo Tribunal Regional Eleitoral de Minas Gerais e pelo Tribunal Superior Eleitoral, em processos relativos às Eleições 2018, referente à ordem de suspensão das propagandas eleitorais veiculadas no Rádio e na Televisão. Devido à relação com o tema, apresentou-se um breve conceito de discurso de ódio relacionado à campanha eleitoral, limitando sua análise à parte da ofensividade e restrição à liberdade de expressão.
} 
excluí-lo ou bani-lo do discurso democrático. ${ }^{14}$ De acordo com a posição oposta, considerações compensatórias, como liberdade, democracia ou verdade exigem que nós o toleremos. $^{15}$

A divergência que muitas vezes é traçada no discurso de ódio (hate speech) ocorre entre a visão mais defendida nos Estados Unidos da América, que tende a se opor à proibição do discurso de ódio, com fundamento constitucional na $1^{\text {a }}$ Emenda à Constituição americana, a qual proíbe o Congresso Nacional de publicar leis que restrinjam a liberdade de expressão, e o resto do mundo, que tende a abraçá-la, com fundamento na Convenção Internacional sobre a Eliminação de Todas as Formas de Discriminação Racial (promulgada no Brasil pelo Decreto 65.810 de 08 de dezembro de 1969) e o Pacto Internacional sobre Direitos Civis e Políticos (promulgado no Brasil pelo Decreto 592 de 6 de julho de 1992). A preocupação, estabelecida em debates por diversos doutrinadores, envolve a discussão acerca da possibilidade de censura e os benefícios e malefícios na regulação do discurso, pois seria extremamente difícil demarcar aquilo que é compatível ou não com a liberdade de expressão.

Mas, mesmo nos Estados Unidos da América, as "fighting words", bem como ameaças e assédios direcionados são geralmente proibidos (tese do imminent lawless action e do imminent danger). Todavia, apesar de discursos de supremacia racial branca, queima da cruz em frente à residência de uma família afroamericana e exortações homofóbicas na cerimônia fúnebre de um soldado americano, a Suprema Corte Americana decidiu pelo livre discurso. ${ }^{16}$

\footnotetext{
${ }^{14}$ Jeremy Waldron, entre outros, argumentou com veemência que o discurso público de ódio agride a dignidade de seus alvos (WALDRON, 2012).

15 Maxime Lepoutre, em Hate Speech in Public Discourse: A Pessimistic Defense of Counterspeech, apresenta uma crítica ao artigo de Waldron, afirmando que: "Jeremy Waldron, among others, has forcefully argued that public hate speech assaults the dignity of its targets. Without denying this claim, I contend that it fails to establish that bans, rather than counterspeech, are the appropriate response. By articulating a more refined understanding of counterspeech, I suggest that counterspeech constitutes a better way of blocking hate speech's dignitarian harm. In turn, I address two objections: according to the first, which draws on contemporary philosophy of language, counterspeech does not block enough hate speech; according to the second, counterspeech blocks too much speech. Although these objections. should qualify our optimism regarding counterspeech, I demonstrate that each can be turned, with even greater force, against hate speech bans". O autor sustenta que, ao articular uma compreensão mais refinada do contradiscurso, este constitui uma maneira melhor de bloquear o dano dignitário da fala de ódio (LEPOUTRE, 2017).
}

${ }^{16}$ Os leading cases mais famosos são Brandenburg v. Ohio (1969), R.A.V. v. City of St. Paul (1992) e Snyder v. Phelps (2011). 
Maxime Lepoutre cita que Jeremy Waldron (que tem uma visão de restrição do discurso de ódio) parte de uma imagem atraente da justiça, segundo a qual a justiça exige que se trate os seres humanos com dignidade. Isso significa que o status de cidadão como membros livres e iguais da sociedade - sua dignidade - deve ser reconhecido e sustentado por outras pessoas.

Com base na ideia de Rawls de uma sociedade bem ordenada, Waldron (2012, p. 65) argumenta que a justiça exige algo mais. Os cidadãos também devem saber que seus pares mantêm sua boa reputação. Sem a garantia de que sua dignidade é segura, os cidadãos não podem desfrutar plenamente de sua boa reputação. De fato, essa garantia é necessária para que os cidadãos busquem seus objetivos e participem da vida civil e política sem medo ou vergonha:

\begin{abstract}
“ (...) devemos nos preocupar com o que nossa sociedade parece. Pense nos passos e cantos dos neonazistas ou em um cidadão muçulmano confrontado com jornais que descrevem muçulmanos como animais depravados sexualmente. Por nossas intuições mais fortes, isso não é o que uma sociedade bem ordenada e justa parece ser. Ao negar publicamente o status de seus alvos como iguais, o discurso de ódio afeta o modo como a sociedade se parece, de modo a minar a segurança pública. Além disso, o discurso público de ódio alcança outras pessoas odiosas, para assegurar-lhes que não estão sozinhos. Ao fazê-lo, substitui a segurança da dignidade pela certeza do ódio" (tradução nossa). ${ }^{17}$
\end{abstract}

Mas Lepoutre enfatiza que o principal problema com o argumento de Waldron é que a comparação que ele faz entre a sociedade que proíbe o discurso do ódio no discurso público e a sociedade que permite tal discurso é excessivamente idealista em relação ao primeiro e excessivamente não-caridoso em relação ao segundo. Tomando por base a sociedade que bane

\footnotetext{
${ }^{17}$ Waldron,teve como objetivo central reunir argumentos em defesa da implementação de leis que proíbam ou restrinjam o discurso de ódio (hate speech). Para ele, o discurso de ódio não é problemático apenas porque contribui para a gradual degradação de direitos ou porque gera risco de violência. O discurso de ódio é problemático porque também representa um ataque direto à reputação e à dignidade das suas vítimas. Waldron continua: "What is the harm in hate speech? Waldron starts from an appealing picture of justice, whereby justice requires treating human beings with dignity. In the first place, this means that citizens' status as free and equal members of Society in good standing - their dignity - should be recognized and upheld by other citizens. However, drawing on Rawls's idea of a well-ordered society, Waldron argues that justice requires something more. Citizens must also know that their peers uphold their good standing. Absent the assurance that their dignity is safe, citizens cannot fully enjoy their good standing. Indeed, this assurance is necessary for citizens to pursue their aims and participate in civil and political life without fear or shame".
} 
o ódio primeiro, uma das preocupações mais comumente invocadas com essa sociedade é que ter uma fala reprimida prejudica significativamente a liberdade ou autonomia.

Cita também que a ascensão de partidos europeus de extrema-direita, cuja retórica é muitas vezes saturada de xenofobia, está embasada em cidadãos economicamente descontentes e que sentem, justificadamente, que suas vozes têm sido ignoradas. A supressão do discurso de ódio parece ter um custo moral substancial: diminui a liberdade de muitos dos cidadãos e, portanto, o conhecimento acerca dos fundamentos do problema e da demanda dessas pessoas. De fato, injustiças podem ser problemas estruturais que geram violência naqueles que a sofrem. Consequentemente, vítimas de injustiças sociais tendem a ser intolerantes e violentas. Nesse ponto, pode-se fazer uma conexão com Arendt, conforme antes mencionado, de que o ódio só surgiria onde há razões para suspeitar que as condições podem ser mudadas, quando o senso de justiça for ofendido.

Por conseguinte, Lepoutre entra com o contradiscurso como uma arma mais adequada na luta contra o discurso de ódio. Para seu propósito, o principal problema é: defensores das proibições de discurso de ódio devem mostrar que essas proibições legais são melhores do que um contradiscurso estatal. Mesmo na teoria, proibições parecem singularmente pouco promissoras com respeito ao "discurso codificado", qual seja, aquele discurso que não é direto, pois através da alteração da linguagem passa-se a mensagem, a ideia, com uma forma diferente de falar. Além disso, dois outros problemas surgem especificamente para proibições:

\footnotetext{
Primeiro, proibições legais são ferramentas contundentes, enquanto a própria existência do discurso de ódio codificado mostra como o discurso de ódio pode facilmente mudar de forma. Mesmo se identificar e proibir o discurso de ódio codificado, seus falantes podem facilmente adotar novos códigos para evitar a proibição. Segundo, palavras codificadas são generalizadas e envolvem termos usualmente comuns, podendo ser banidas mesmo em casos nos quais não se referem a discurso de ódio (LEPOUTRE, 2017).
}

Ainda, tece que seria improvável que discursos de ódio tendem a não proliferar em sociedades que o banem, porque, por exemplo, mesmo em países da Europa onde se tem proibições, há existência desses discursos, mormente em linguagens obscuras. Dessa feita, apresenta-se nessa conjuntura uma das dificuldades de se dar uma resposta fechada à problemática. 
Outra dificuldade que podemos citar refere-se justamente à violência objetiva, pois se conclui que não basta atacar o discurso, mas identificar suas causas/condições, tendo em vista que ele (discurso com ódio) pode estar relacionado, em regra, a insatisfações sociais inerentes ao sistema econômico-social no qual vivem as pessoas e que o ódio surgiria onde há razões para suspeitar que as condições podem ser mudadas. Sem pretensão de defesa da violência, mas esse ponto parece ser o fundamento de Žižek para considerar que o ódio é um dos elementos de luta do homem, partindo da rejeição de uma falsa antiviolência e chegar à aceitação da violência emancipatória, para afirmar que estigmatizar a violência é uma mistificação que colabora no processo de tornar invisíveis as formas de violência social.

Outra questão interessante refere-se ao discurso na internet. Hajime Watanabe, Ondher Bouazizi e Tomoaki Ohtsuki, no artigo "Discurso de Ódio no Twitter (Hate Speech on Twitter: A Pragmatic Approach to Collect Hateful and Offensive Expressions and Perform Hate Speech Detection)", examinam que na disseminação da internet e redes sociais o problema se torna mais grave, já que as interações entre as pessoas são indiretas e o discurso tende a ser mais agressivo porque as pessoas se sentem mais seguras atrás dessa ferramenta (WATANABE; BOUAZIZI; OHTSUKI, 2018).

Os autores, em pesquisa estatística realizada, classificaram três tipos de classes de palavras no Twitter: a) limpas: que não contêm conteúdo ofensivo; b) ofensivo: esta classe contém tweets ofensivos, mas que não se caracterizam como discurso odioso; c) odioso: esta classe inclui tweets ofensivos que abrangem expressões racistas e segregativas. Ou seja, nem toda expressão ofensiva pode ser enquadrada como discurso de ódio. ${ }^{18}$

No mesmo artigo, cita que os sites do Facebook, Youtube e Twitter proíbem o discurso de ódio e tentam localizar esse tipo de discurso. Contudo, é extremamente difícil controlar o conteúdo postado por todos os usuários, em especial se o discurso está escondido atrás de palavras que não são diretamente "odiosas" e expressões não claras. ${ }^{19}$

\footnotetext{
${ }^{18}$ Os autores afirmam que o discurso de ódio se refere ao uso de linguagem agressiva, violenta ou ofensiva, visando um grupo específico de pessoas que compartilham uma propriedade comum, se esta propriedade é seu gênero (ou seja, sexismo), seu grupo étnico ou raça (ou seja, racismo) ou suas crenças e religião. Embora a maioria das redes sociais online e sites proíbam o uso de ódio no discurso, o tamanho dessas redes e sites torna quase impossível controlar todo o seu conteúdo.

${ }^{19}$ Propuseram, assim, uma abordagem para detectar expressões de ódio em Twitter. A abordagem é baseada em padrões que são coletados automaticamente.Esses padrões e unigramas são usados posteriormente, entre outros,
} 
Noutro ponto, também se referindo à linguagem, Rosenberg elabora o processo para se chegar à linguagem não violenta. Primeiro, se refere à observação do que está de fato acontecendo numa situação, sem realização de julgamento, mas simplesmente dizer o que nos agrada ou não naquilo que as pessoas estão fazendo. Em seguida, identificar como se sente ao observar aquela ação; em terceiro lugar, reconhecer quais de nossas necessidades estão ligadas aos sentimentos que identificamos e, por último, o que pedimos para enriquecer nossa vida (ROSENBERG, 2006).

Para o autor, há uma diferença entre juízos de valor com julgamento moralizadores. Todos fazem juízos de valores sobre qualidades que admiramos na vida, já julgamentos moralizadores ocorrem quando se pensa que pessoas e comportamentos estão em desacordo com nossos juízos de valor.

Menciona, ainda, uma pesquisa feita por O.J. Harvey, professor de psicologia na Univerdade de Colorado, que tomou amostras aleatórias de obras literárias de países e tabulou a frequência das palavras que classificam e julgam as pessoas. Seu estudo constatou elevada correlação entre o uso frequente dessas palavras e a incidência da violência. Ainda,em $75 \%$ dos programas exibidos nos horários em que existe maior probabilidade de as crianças americanas estarem assistindo à TV, o herói ou mata as pessoas ou espanca, em "clímax" de espetáculo. Conclui que talvez toda a violência, verbal, psicológica ou física, entre familiares e nações, esteja num tipo de pensamento que atribui a causa do conflito ao fato de adversários estarem errados, e a correspondente incapacidade de pensar em si mesmo ou nos outros em termos de vulnerabilidade.

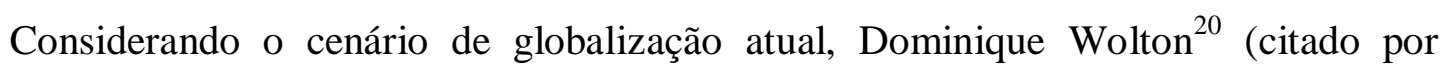
GOULART, 2005) escreve que há a comunicação técnica, a econômica e a que diz respeito ao modelo cultural e social. Embora haja muita informação, há uma distância entre comunicação e informação. O desafio da comunicação está no homem, e não na técnica de comunicação. $\mathrm{Na}$ democracia, deve-se dar lugar à alteridade, ao pluralismo de opiniões e, para ele, os valores da tradição devem ser reintroduzidos para haver modernidade.

como recursos para treinar um algoritmo de aprendizado de máquina. Nos experimentos, um conjunto de teste composto de tweets mostrou que a abordagem atinge uma precisão igual para 87,4\% ao detectar se um tweet é ofensivo ou não (classificação binária), e uma precisão igual para 78,4\% ao detectar se um tweet é odioso, ofensivo ou limpo (classificação ternária).

${ }^{20}$ WOLTON, Dominique. Elogio do Grande Público. Uma teoria crítica da televisão. Tradução José Rubens Siqueira. São Paulo: Ática, v. 52, 1996. 
Relata, ainda, que quanto mais globalização, mais povos vão desejar manter suas identidades e recuperar suas raízes. Se há respeito à diversidade cultural, há emancipação.

Por fim, não se pode deixar de mencionar que, no âmbito internacional, a Convenção Europeia de Direitos Humanos prevê a liberdade de expressão, em seu artigo 10, compreendendo-se nesta a liberdade de opinião, de receber ou de transmitir informações ou ideias sem que possa haver ingerência de quaisquer autoridades públicas e sem considerações de fronteiras. Contudo, estabelece que seu exercício implica deveres e responsabilidades, podendo ser submetido a certas formalidades, condições, restrições ou sanções previstas em lei, que constituam providência necessárias, numa sociedade democrática, para a segurança nacional, a integridade territorial ou a segurança pública, a defesa da ordem e a prevenção do crime, a proteção da saúde ou da moral, a proteção da honra ou dos direitos de outrem, para impedir a divulgação de informações confidenciais, ou para garantir a autoridade e a imparcialidade do poder judicial.

No âmbito da proibição da discriminação, estabelece que o gozo dos direitos e liberdades deve ser assegurado sem quaisquer distinções, tais como as fundadas no sexo, raça, cor, língua, religião, opiniões políticas ou outras, a origem nacional ou social, a pertença a uma minoria nacional, a riqueza, o nascimento ou qualquer outra situação.

\section{CONCLUSÃO}

O presente trabalho parte da concepção de que, para se compreender a violência contida em discursos de ódio, é imprescindível fazer uma breve análise da violência em sua concepção filosófica, e do homem no seu aspecto filosófico, como valor, como aquele que possui a faculdade de outorgar sentido aos atos e às coisas.

Discorreu-se acerca da concepção de violência de Slavoj Žižek, no sentido de que na sociedade contemporânea é comum a violência objetiva, aquela inerente ao estado "normal" das coisas, por causa da ideologia subjacente ao discurso liberal.

Atualmente, não se pode falar de discurso de ódio sem se referir à violência nele contida, devido ao uso da linguagem agressiva, violenta ou ofensiva, que visa atingir um 
grupo específico de pessoas que compartilham uma identidade comum, e a comunicações que negam a condição de outros membros da sociedade como cidadãos livres e iguais.

Em que pese a agressividade contida nele (discurso de ódio), para alguns estudiosos, devido à liberdade de expressão e à dificuldade para identificá-lo, não há justificativas para a exclusão ou restrição de qualquer discurso. Nesse ponto, considerações compensatórias como liberdade, democracia ou verdade exigem sua tolerância. Para outros, contudo, o dano envolvido no discurso de ódio justifica excluí-lo ou bani-lo do discurso democrático. Não há uma resposta fechada sobre qual entendimento é o correto e qual é o errado, devido às dificuldades na problemática posta, uma vez que o discurso com ódio, para além de discriminações, pode estar relacionado a insatisfações sociais inerentes ao sistema econômicosocial no qual vivem as pessoas, e, em regra, à violência objetiva e sistêmica, as quais não são facilmente identificadas e banidas.

Por derradeiro, entende-se que a comunicação no mundo globalizado requer pluralismo de opiniões e respeito ao outro, sendo a democracia a arma mais importante no discurso e no contradiscurso.

\section{REFERÊNCIAS BIBLIOGRÁFICAS}

ARENDT, Hannah. Da violencia. Brasilia: Ed. da Universidade de Brasilia, 1985.

ASKOLA, Heli. Taking the Bait? Lessons from a Hate Speech Prosecution. Published by Cambridge University Press. Disponível em: http://muse.jhu.edu/journals/jls/summary/v030/30.1.askola.html>. Acesso em: 30 out. 2020. BRASIL. Decreto 65.810, de 08 de dezembro de 1969. Promulga a Convenção Internacional sobre a Eliminação de todas as Formas de Discriminação Racial. Disponível em: < https://www2.camara.leg.br/legin/fed/decret/1960-1969/decreto-65810-8-dezembro-1969407323-publicacaooriginal-1-pe.html>. Acesso em: 23 mar. 2021.

BRASIL. Decreto 592, de 6 de julho de 1992. Pacto Internacional sobre Direitos Civis e Políticos. Disponível em < http://www.planalto.gov.br/ccivil_03/decreto/19901994/d0592.htm>. Acesso em: 23 mar. 2021.

Convenção para a proteção dos Direitos do Homem e das Liberdades Fundamentais. Disponível em: <http://www.echr.coe.int/Documents/Convention_POR.pdf> Acesso em: 18 mar. 2021.

GOULART, Alexander. A comunicação de massa como condição para a democracia. Observatório da Imprensa. Edição 331. Ano 21, n. 1130. 2005. Disponível em: 
http://observatoriodaimprensa.com.br/diretorio-academico/a-comunicacao-de-massa-comocondicao-para-a-democracia/. Acesso em: 07 jan. 2021.

HOBBES, Thomas. Do cidadão. São Paulo, Martins Fontes, 2002. Leviatã. São Paulo, Martins Fontes, 2008.

INGLEHART, Ronald. La nuova partecipazione nelle società post-industriali. Rivista Italiana di Scienza Politica, an. XVIII, n. 3, dic. 1988.

LEPOUTRE, Maxime Charles. Hate Speech in Public Discourse: A Pessimistic Defense of Counterspeech. Social Theory and Practice. Vol. 43, N. 4 (October 2017): 851-883. Disponível em: < https://www.repository.cam.ac.uk/handle/1810/269589>. Acesso em: 07 jan. 2021.

LOMBROSO, Cesare. O Homem Delinquente. Tradução: Sebastian José Roque. 1. Reimpressão. São Paulo: Ícone, 2010.

MASCARO, Alysson Leandro. Filosofia do Direito. $6^{\text {a }}$ ed. ver. e atual.- São Paulo: Atlas, 2018.

MODENA. Maura Regina. Conceitos e formas de violência. Caxias do Sul, RS: Educs, 2016. PEREIRA. Rodolfo Viana. Ensaio sobre o ódio e a intolerância na propaganda eleitoral. Direitos Políticos, Liberdade de Expressão e Discurso de Ódio. v. 1. Belo Horizonte: IDDE, 2018.

PEREIRA, Rodolfo Viana. Direitos políticos, liberdade de expressão e discurso de ódio. V. 3. Belo Horizonte: IDDE, 2019.

PERINE, Marcelo. A filosofia de Eric Weil. Sintese, Belo Horizonte, n. 49, p. 95-100, 1990.

POPPER, Karl Raimund. A sociedade aberta e seus inimigos. Belo Horizonte, ed. Itatiaia: São Paulo, ed. da Universidade de São Paulo, 1974.

REALE, Miguel. Filosofia do direito. 19. ed.- São Paulo: Saraiva, 1999.

ROCHA, Giselle Morais. A Desconstrução da Imagem e a Propaganda Eleitoral no Rádio e Televisão In: PEREIRA, Rodolfo Viana (Coord.) Direitos políticos, liberdade de expressão e discurso de ódio. V. 3. Belo Horizonte: IDDE, 2019.

ROSENBERG, Marshall B. Comunicação Não-Violenta: técnicas para aprimorar relacionamentos pessoais e profissionais. São Paulo: Ágora, 2006.

SCHWADEL, Philip; GARNEAU, Christopher R. H. An age-period-cohort analysis of political tolerance in the United States. The Sociological Quarterly, v. 55, 2014.

SOUZA, Artur de Britos Gueiros. Inovações no direito penal econômico. Contribuições criminológicas, político-criminais e dogmáticas. Brasília: ESMPU, 2011.

SUTHERLAND, Edwin H; El delito de cuello blanco. Tradução de Rosa del Omo. Madrid: La Piqueta, 1999.

SPRANGER, Eduardo. Formas de Vida, Rev. Do Occidente, Buenos Aires, 1948.

VAN SPANJE, Joost e Claes De Vreese. The good, the bad and the voter: the impact of hate speech prosecution of a politician on electoral support for his party. Party Politics, v.21, n.1, 2015. Disponível em: < https://claesdevreese.files.wordpress.com/2015/08/vanspanjedevreese_2013.pdf>. Acesso em: 23 mar. 2021. 
WALDRON. Jeremy. The Harm in Hate Speech. Harvard University Press. Cambridge, Massachusetts. London, 2012. Dngland. Disponível em: <http://www.hup.harvard.edu/catalog.php?isbn=9780674416864>. Acesso em: 20 fev. 2021.

WATANABE, Hajime; BOUAZIZI, Ondher; OHTSUKI, Tomoaki. Hate Speech on Twitter: A Pragmatic Approach to Collect Hateful and Offensive Expressions and Perform Hate Speech Detection. Graduate School of Science and Technology, Keio University, Yokohama 223-8522, Japan. 2018. Disponível em: http://www.ieee.org/publications_standards/publications/rights/index.html>. Acesso em: 18 mar 2021.

WEIL, Eric. Filosofia politica. Sao Paulo: Loyola, 1990.

ŽIŽEK, Slavoj. Violência: seis reflexões laterais. Trad. de Miguel Serras Pereira. São Paulo: Boitempo, 2014. 